\title{
A Mars VTOL Aerobot - Preliminary Design, Dynamics and Control
}

\author{
Hanbing Song (AIAA student member) and Craig Underwood (IEEE member) \\ Surrey Space Centre \\ University of Surrey \\ Guildford, GU2 7XH, U.K. \\ 0044-1483686027 \\ hanbing.song@surrey.ac.uk, c.underwood@surrey.ac.uk
}

\begin{abstract}
In this paper, we propose the use of a novel fixed-wing vertical take-off and landing (VTOL) aerobot. A mission profile to investigate the Isidis Planitia region of Mars is proposed based on the knowledge of the planet's geophysical characteristics, its atmosphere and terrain. The aerobot design is described from the aspects of vehicle selection, its propulsion system, power system, payload, thermal management, structure, mass budget, and control strategy and sensor suite. The aerobot proposed in this paper is believed to be a practical and realistic solution to the problem of investigating the Martian surface. A six-degreeof-freedom flight simulator has been created to support the aerobot design process by providing performance evaluations. The nonlinear dynamics is then linearized to a state-space formulation at a certain trimmed equilibrium point Basic autopilot modes are developed for the aerobot based on the linearized state-space model. The results of the simulation show the aerobot is stable and controllable. ${ }^{12}$
\end{abstract}

\section{TABLE OF CONTENTS}

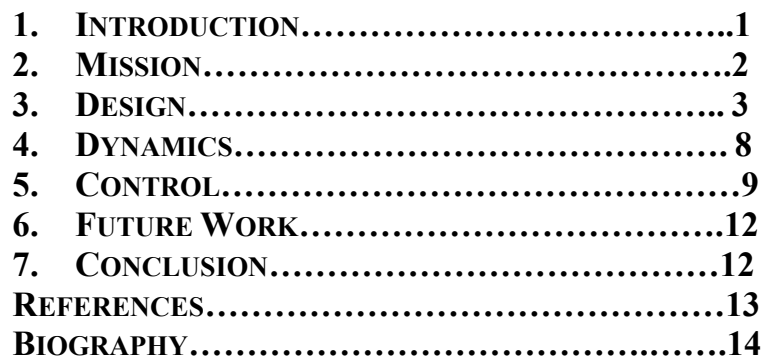

\section{INTRODUCTION}

Since 1960, the exploration of Mars has progressed through three methodologies: Flyby, Orbiter and Lander/Rover. For the next stage of Mars exploration, a novel aerial system (aerobot) is required to guarantee regional coverage of the Martian surface with high resolution sensing for precise investigations of geology and life processes. The existing aerobot proposals fall into four major categories: balloons, airships, fixed-wing airplanes and rotorcraft. It is hard to establish which one is superior. The choice of vehicle type will depend on the mission budget and flight profile. The French/Russian Mars Aerostat [1] proposes a balloon that

\footnotetext{
${ }^{1}$ 1-4244-0525-4/07/\$20.00@ 2007 IEEE

2 IEEEAC paper \#1138, Version 3, Updated Nov, 082006
}

would float at $4 \mathrm{~km}$ altitude with a $5500 \mathrm{~m}^{3}$ cylindrical overpressure envelope. JPL has proposed MABVAP (Mars Aerobot Validation Program), which would use a superpressure balloon [2]. Gundlach proposed a Solar-Powered Hybrid Airship, which is a hybrid mix of aircraft and airship [3]. A lot of fixed-wing airplane missions and conceptual designs were also proposed by various institutes [4][10][11][12][13]. The well-known ARES (Aerial Regional-scale Environmental Survey of Mars) proposed by NASA Langley is targeted to explore the Martian Southern Highlands [4][5]. The other airplane missions and specifications are summarized in Table 1. Young proposed two rotorcraft concepts - the coaxial helicopter and the tilt rotor [6]. Fielding proposed MASSIVA with the combination of rotor and flying wing [7].

The biggest challenge in Mars airplane design is the nature of Martian atmosphere. The low atmospheric density, low pressures, low temperatures, and lack of oxygen, place strict constraints on the design of the aerobot. The atmospheric characteristics are summarized in Table 2. The surface gravity on Mars is $3.71 \mathrm{Nkg}^{-1}$, about $1 / 3^{\text {rd }}$ of that of Earth. The average atmospheric pressure on the Martian surface is only $0.69 \%$ of that of the Earth's at sea level. The day-today pressure variation is low in spring and summer but higher in autumn and winter. The pressure varies from $1 \mathrm{kPa}$ in the deepest basins to $0.1 \mathrm{kPa}$ at the top of the Olympus Mons [8] - cf. Earth's average sea level pressure of 101 $\mathrm{kPa}$. The atmospheric density distribution on Mars also changes with altitude, ranging from $0.028 \mathrm{kgm}^{-3}$ on the northern plain to $0.005 \mathrm{kgm}^{-3}$ on the peak of Olympus Mons. The average density is very low, roughly $1 \%$ of that at Earth's sea level. These low densities and pressures demand that any Martian air vehicle be much larger than its counterpart on Earth in order to generate the required lift. Even so, the lift forces are small, so Mars air vehicles must also be extraordinarily lightweight. For a fixed wing airplane, a high cruise velocity can offset, to some extent, the need for a large wing area. However, the penalty for high velocity is a relatively high power demand - which also tends to couple to low flight endurance. The major atmospheric constituent is $\mathrm{CO}_{2}$, which means all the airbreathing propulsion systems relying on $\mathrm{O}_{2}$ from incoming air as an oxidizer are not viable on Mars. The average surface temperature on Mars is $-63{ }^{\circ} \mathrm{C}$ [9], and this varies on a regular daily cycle. In order to maintain a particular temperature essential for some of the critical scientific payloads and sensors, thermal control is necessary - 
including a high degree of insulation and/or the provision of heaters.
In the following sections, the mission profile is determined based on the Martian environment. The aerobot concept design, its dynamic performance and basic controller design will be discussed in detail.

Table 1. Fixed-wing Airplane

\begin{tabular}{|c|c|c|c|c|c|c|c|c|}
\hline $\begin{array}{l}\text { Vehicle } \\
\text { Proposal }\end{array}$ & $\begin{array}{l}\text { Mass } \\
(\mathrm{kg})\end{array}$ & $\begin{array}{l}\text { Wing } \\
\text { Span } \\
(\mathrm{m})\end{array}$ & Propulsion & $\begin{array}{l}\text { Endurance } \\
\text { \& Range }\end{array}$ & $\begin{array}{l}\text { Cruise } \\
\text { Speed } \\
\left(\mathrm{ms}^{-1}\right)\end{array}$ & $\begin{array}{l}\text { Cruise } \\
\text { Altitude }\end{array}$ & Control & navigation \\
\hline $\begin{array}{l}\text { ARES } \\
\text { Airplane } \\
{[4][5]}\end{array}$ & $\begin{array}{l}\text { 150wet / } \\
101 \text { dry }\end{array}$ & 6.25 & $\begin{array}{l}\text { Liquid Rocket } \\
\text { (MMH/MON-3) }\end{array}$ & $\begin{array}{l}1 \text { hour, } \\
>500 \mathrm{~km}\end{array}$ & 145 & $\begin{array}{l}1-2 \mathrm{~km} \\
\text { above } \\
\text { surface }\end{array}$ & $\begin{array}{l}\text { Flaprons, } \\
\text { ruddervators }\end{array}$ & $\begin{array}{l}\text { Inertial, } \\
\text { radar, air } \\
\text { data }\end{array}$ \\
\hline $\begin{array}{l}\text { Kitty Hawk } \\
{[10]}\end{array}$ & 135 & 9.75 & $\begin{array}{l}\text { Rear-mounted } \\
\text { propeller, } \\
\text { Hydrazine }\end{array}$ & $\begin{array}{l}3 \text { hours, } \\
1800 \mathrm{~km}\end{array}$ & 160 & $\begin{array}{l}1-9 \mathrm{~km} \text { over } \\
\text { canyon } \\
\text { surface }\end{array}$ & $\mathrm{N} / \mathrm{A}$ & $\mathrm{N} / \mathrm{A}$ \\
\hline AME [11] & 203.8 & 12.4 & $\begin{array}{l}\text { Rocket, } \\
\text { Lithium/hydrogen } \\
\text { peroxide fuel cell }\end{array}$ & $\begin{array}{l}2 \text { flights } \\
\text { ( } 8.8 \text { hours } \\
\text { in total), } \\
3400 \mathrm{~km}\end{array}$ & 110.6 & $\begin{array}{l}\text { Elevation } \\
\text { changes }\end{array}$ & $\begin{array}{l}\text { Elevator, } \\
\text { Aileron, } \\
\text { Rudder }\end{array}$ & $\mathrm{N} / \mathrm{A}$ \\
\hline $\begin{array}{l}\text { Canon- } \\
\text { Flyer } \\
{[12]}\end{array}$ & 20 & 2.2 & $\begin{array}{l}\text { Propeller driven: } \\
\text { Battery powered } \\
\text { electric motor \& } \\
\text { Hydrazine- } \\
\text { powered motor }\end{array}$ & $\begin{array}{l}15 \text { minutes, } \\
130 \mathrm{~km}\end{array}$ & 144 & $\begin{array}{l}500 \mathrm{~m} \\
\text { above } \\
\text { surface }\end{array}$ & $\begin{array}{l}\text { Conventional } \\
\text { control } \\
\text { surface }\end{array}$ & $\begin{array}{l}\text { IMU, Radar, } \\
\text { air data, sun } \\
\text { angle sensor }\end{array}$ \\
\hline $\begin{array}{l}\text { NRL } \\
\text { MATADOR } \\
{[13]}\end{array}$ & $\mathrm{N} / \mathrm{A}$ & 4 & Rocket powered & $\begin{array}{l}45 \text { minutes } \\
-1 \text { hour } \\
300 \mathrm{~km}- \\
400 \mathrm{~km}\end{array}$ & 143 & $4 \mathrm{~km}$ & $\begin{array}{l}\text { Cold-gas } \\
\text { reaction } \\
\text { control } \\
\text { system, thrust } \\
\text { vector }\end{array}$ & N/A \\
\hline
\end{tabular}

Table 2. Atmospheric Features on Mars vs. Earth's Sea Level and 30km High Altitude

\begin{tabular}{|c|c|c|c|}
\hline & Mars & Earth (sea level) & Earth (30480m) \\
\hline Average surface pressure $(\mathrm{kPa})$ & 0.636 at mean radius & 101.3 & 1.3372 \\
\hline Density $\left(\mathrm{kgm}^{-3}\right)$ & $\sim 0.010 \sim 0.020$ & 1.22557 & 0.0131 \\
\hline Average temperature $\left({ }^{\circ} \mathrm{C}\right)$ & -63 & 15 & -40.06 \\
\hline Wind speeds $\left(\mathrm{ms}^{-1}\right)$ & $2-7$ (summer), & $0 \sim 100$ & \\
& $5-10$ (fall), & & \\
& $17-30$ (dust storm) & & 306.2 \\
\hline Speed of Sound $\left(\mathrm{ms}^{-1}\right)$ & 238.2 & 340.3 & Nitrogen $\left(\mathrm{N}_{2}\right)-78.08 \%$ \\
\hline Atmospheric composition & Carbon Dioxide $\left(\mathrm{CO}_{2}\right)-$ & Oxygen $\left(\mathrm{O}_{2}\right)-20.95 \%$ etc. \\
\hline
\end{tabular}

\section{MisSION}

\section{Mission Profile}

It is preferable for our Aerobot to fly over the Northern plain on Mars so that it can take advantage of the relatively higher atmospheric density at low altitude. From the surface topography and roughness of Mars [14], it can be expected that the plains of the northern hemisphere will also provide more suitable landing sites. However, taking insolation into account, the flight path should not be too far away from the equator. Besides the engineering considerations, scientific significance should also be valued. Hence, Isidis Planitia, a nearly circular plain about $1500 \mathrm{~km}$ across, centred at $13^{\circ} \mathrm{N}$, $87^{\circ} \mathrm{E}$, is chosen for this mission, as it lies along the boundary between the ancient highlands in the Southern Hemisphere and the younger plains in the Northern
Hemisphere and it is a good candidate to look for sign of life.

Given the weather data acquired from the NASA JPL Viking missions and others, the best season for the flight would be within the period of northern early spring until summer, when the day-to-day pressure variation and wind speed are small. In this period, the prevailing wind direction will be westwards in the low latitudes of the Northern Hemisphere. Hence, the preferable flying direction should be from the west to the east. The mission will involve 10 flights in order to complete a crossing flight over the Isidis Planitia. 


\section{DESIGN}

\section{Vehicle Selection}

Various vehicle types are compared in Table 3 from the aspects of potential mission objectives.

Mars balloons promise long duration flights that would move with the winds. In the thin atmosphere of Mars, a much larger balloon is required to lift a given payload than on Earth. The aerial deployment and inflation of such a big envelope in the thin Martian atmosphere is still the most challenging problem for the balloon concepts as stated in [1]. In addition, it is relatively difficult for a balloon to survey selected areas of interest on the planet due to the lack of directional control.

A conventional fixed wing airplane has the advantage of being able to provide controlled flight, but it is not capable of VTOL; hence this type of airplane is only suitable for the "one time only" missions as proposed by many researchers. The fixed wing Mars airplane missions typically begin by deploying the airplane in a nose-down attitude, which involves a dive below the cruise altitude in order to establish flight speed, and ends with an uncontrolled crash into the planet's surface. As a compromise, they have to give up the wider coverage and surface sampling. The data transmission is also a big challenge for one time only missions because the huge volume of imagery data that would need to be transmitted within a limited flying period.

The advantage of rotorcraft is their VTOL capability, but such craft are inherently inefficient and slow in cruise. They are also very power-hungry because the rotor has to generate both the lift and the forward thrust in the cruise phase [15]. In addition, the rotary wing will potentially suffer from the supersonic tip speed of the advancing blade and the stalling of the retreating blade at a high angle of attack in thin air. Furthermore, the rotorcraft is less capable of replenishing power from solar cells mounted on its body, because of the relatively small surface area of the vehicle body, so it will be limited to a range of just a few kilometers radius.

Conclusion - Whilst recognizing the ambitious nature of the design, in the proposed aerobot, the combination of fixed wing and VTOL capability will be explored. The advantage of a fixed wing is that it can help to generate lift in cruise, and can carry a solar array on the wing surface for energy replenishment. In addition, with the VTOL capability, the mission profile can be extended to land periodically to take surface samples and carry out contact experiments. The data can be transmitted completely when the aircraft rests on the Martian surface.

Table 3. Comparison of Various Vehicles

\begin{tabular}{|l|c|c|c|c|c|}
\hline \multicolumn{1}{|c|}{$\begin{array}{c}\text { Vehicle } \\
\text { Science objective }\end{array}$} & $\begin{array}{c}\text { Balloon/ } \\
\text { Airship }\end{array}$ & Glider & $\begin{array}{c}\text { Fixed wing } \\
\text { Airplane }\end{array}$ & Helicopter & $\begin{array}{l}\text { VTOL+ } \\
\text { Airplane }\end{array}$ \\
\hline High spatial resolution image and spectroscopy & $\checkmark$ & $\checkmark$ & $\checkmark$ & $\checkmark$ & $\checkmark$ \\
\hline High special resolution magnetic survey & & & $\checkmark$ & $\checkmark$ & $\checkmark$ \\
\hline Regional-scale high resolution geological survey & $\checkmark$ & & $\checkmark$ & Limited & $\checkmark$ \\
\hline Controlled/Predefined flight & Limited & Limited & $\checkmark$ & $\checkmark$ & $\checkmark$ \\
\hline High volume of data transmission & Limited & & & $\checkmark$ & $\checkmark$ \\
\hline Multiple surface sampling & $\checkmark$ & & & $\checkmark$ & $\checkmark$ \\
\hline
\end{tabular}

\section{Propulsion System}

Three possible solutions for the propulsion system are: Electrical Propulsion Systems, Combustion Engine Systems, and Rocket Systems. Air-breathing jet engines are not feasible on Mars as the carbon dioxide jet engine is still in the early stage of development [16]. Rocket propulsion systems can work without oxygen, but these have to carry on-board sufficient propellant for the entire mission, which would limit the total number of VTOL manoeuvres and hence the duration of this particular mission. In such circumstances, an electrical propulsion system promises to be an advantageous solution because the energy it uses can be replenished by means of solar panels. Although the operation of rotor blades in the low Reynolds Number and high subsonic Mach number environment of Mars poses some problems, the Earth-bound Pathfinder series of aircraft for high altitude long endurance (HALE) has proved the feasibility of such propulsion systems by flying successfully at a $30 \mathrm{~km}$ altitude, which provides a similar aerodynamic regime to that of the surface atmosphere on the Mars [17]. Furthermore, the development of high-capacity and lowweight brushless DC motors for Terrestrial Unmanned Aerial Vehicle (UAV) will also contribute to this aerobot [18].

There are various ways to realize the VTOL maneuver capability, basically from three categories: augmented power plant for hover (ejector, ducted propeller/fan, rotor), same propulsion system for both hover and cruise (tilt shaft, tilt prop, tilt duct, tilt wing, tilt rotor, tilt jet, deflected slipstream, vectored thrust, tail sitter), and separate propulsion system for hover and cruise. Further details regarding each type of VTOL concepts can be found in [19]. It is desirable to use the same propulsion system for both hovering and cruise. But normally the power needed for hovering and cruise does not match well. For the proposed mission, the power needed for cruise is less than $20 \%$ of that required for hovering. In addition, the stowing and 
deployment of the tilt rotors/jets could be quite complicated. Hence, in the proposed aerobot, we adopt the idea of ducted rotors for VTOL maneuver and separate propellers for the forward flight.

VTOL Propulsion-The four, three, two, one rotor and coaxial counter rotating rotor configurations, as shown in Figure 1, were analyzed for the given design requirements and constraints:

○ To lift a $25 \mathrm{~kg}$ aircraft

- To be stowed into an aeroshell of diameter $2.6 \mathrm{~m}$

○ $\quad$ Rotor blade tip speed Mach Number $<0.8$

- Rotor blade stall angle of attack $\alpha<20 \mathrm{deg}$

By assuming that the propeller can provide the required lift, we can calculate the induced velocity $\left(v_{i}\right)$ and the required thrust coefficient $\left(C_{T}\right)$. Based on steady linearized aerodynamics, the pitch angle $(\phi)$, relative inflow angle $(\chi)$, and effective angle of attack $(\alpha)$ can be calculated [20]. The results of the analysis are shown in Table 4 . The effective angle of attack from the 4 rotor, 3 rotor and 2 rotor configurations are all over the given stall angle of $20^{\circ}$. They all require high thrust coefficients, which turn out to be unrealizable because the blade has already stalled before generating the required thrust. The single rotor configuration is the most efficient in terms of lift and power, whereas, the inherent torque effect of single rotor leads to additional rotor or thruster on the tail, which adds on the weight. In addition, a $2.6 \mathrm{~m}$-diameter rotor leaves no room for the rest of the craft. However, the coaxial configuration offers both the anti-torque effect of contra-rotation and an appropriate diameter, benefiting from its compactness. Hence, the coaxial configuration is chosen for the VTOL propulsion system.
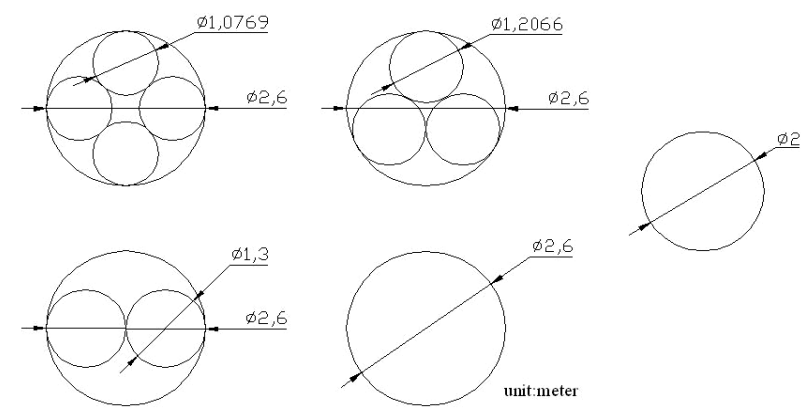

Figure 1 - Rotor Configurations

Table 4. Comparison of various rotor configurations

\begin{tabular}{|l|l|l|l|l|l|}
\hline & 4 rotor & 3 rotor & 2 rotor & 1 rotor & Coaxial \\
\hline Diameter $(\mathrm{m})$ & 1.0769 & 1.2066 & 1.3 & 2.6 & 2.0 \\
\hline Area $\left(\mathrm{m}^{2}\right)$ & 0.9108 & 1.1434 & 1.3273 & 5.3093 & 3.1416 \\
\hline $\mathrm{C}_{\mathrm{T}}$ & 0.0510 & 0.0542 & 0.07 & 0.0350 & 0.0296 \\
\hline$\phi(\mathrm{deg})$ & 37.834 & 39.75 & 49.166 & 27.914 & 24.432 \\
\hline$\alpha(\mathrm{deg})$ & 25.811 & 27.372 & 35.157 & 17.909 & 15.22 \\
\hline
\end{tabular}

Forward Propulsion-An electrical motor/propeller system will be used for the forward propulsion. This would give the associated advantage of multiple uses, with renewable energy via solar panels. Indeed, as the thrust level required from the forward propulsion engines is very much less than the thrust required from the lift engines, it was calculated that we could sustain these engines with power directly generated from solar cells, provided the entire upper lifting surface is covered in solar cell [15].

Despite the promise of renewable energy, the propeller will work in an extraordinarily challenging environment of high rotor tip speed, very low Reynolds number and high advance ratio. For this particular aerobot, the Reynolds number for the propeller is expected to be about 50,000 and the advance ratio $(J)$ is expected to be about 0.8 . As most of the earth-bound propellers provide the peak thrust coefficient and efficiency when the advance ratio is 0.3 , a specific propeller needs to be designed to provide the best performance.

Three low Reynolds number airfoil sections are chosen for detailed investigation of this propeller, including SD8000, SD7032d and S1223. The airfoil section coordinates, lift curves and drag polar curves at $R e=60,000$ (the closest value to the Reynolds number expected for which measured data are available) are shown in Figure $2 \& 3$. The data are obtained from the UIUC airfoil database [21]. The S1223 is well known as a high lift low Reynolds number airfoil. The highly cambered airfoil offers the highest lift coefficient when the angle of attack is less than $5 \mathrm{deg}$, but the penalty is the higher drag coefficient. The SD7032d offers the highest lift coefficient among the Selig/Donovan series of low Reynolds number airfoils, but its drag coefficient varies and is higher than that of SD8000 before stalling. Hence, the SD8000 is chosen as the appropriate airfoil for the propeller.

Three propeller geometries have been investigated. Their chord and twist angle $\beta$ along the propeller radius are shown in Figure 4. With the information of the aerodynamic characteristics of SD8000 and the propeller geometry, the thrust coefficient $\left(C_{t}\right)$ and power coefficient $\left(C_{p}\right)$ vs. advance ratio $(J)$ can be calculated based on the blade element method (BEM) [20], results shown in Figure 5. The thrust coefficient of prop3 is much smaller than those of the other two propellers due to the smaller chord/solidity. The performances of prop1 and prop2 are quite close. However, both of them reach a peak thrust coefficient at $\mathrm{J}=0.4$, then deteriorate quickly as $\mathrm{J}$ increases further, because the effective angle of attack decreases as $\mathrm{J}$ increases. An enhanced version of propeller is then obtained by increasing the twist angle of the blade of prop2. The results show that the propeller performance has been improved dramatically, though slightly degraded when $\mathrm{J}$ is small. This enhanced propeller is used for this aerobot. 


\section{Airfoil Sections}

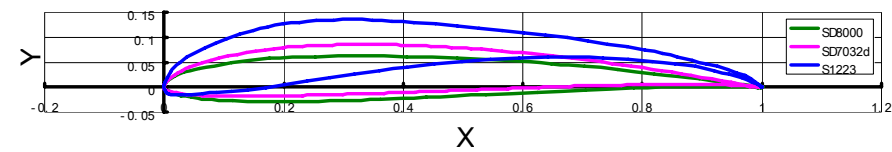

Figure 2 - Airfoil Sections Coordinate


Figure 3 - Aerodynamic Characteristics of 2-D Airfoil
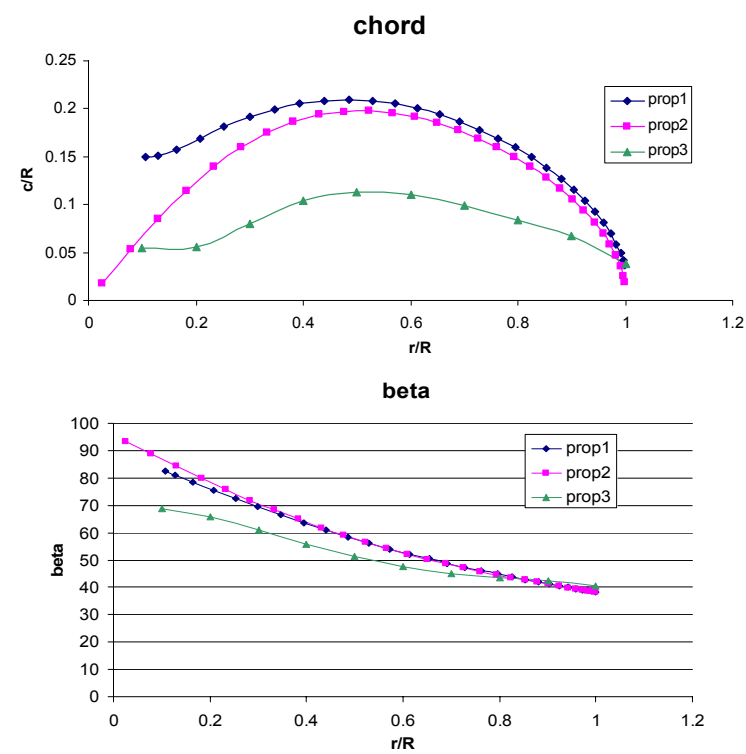

Figure 4 - Propeller Geometry
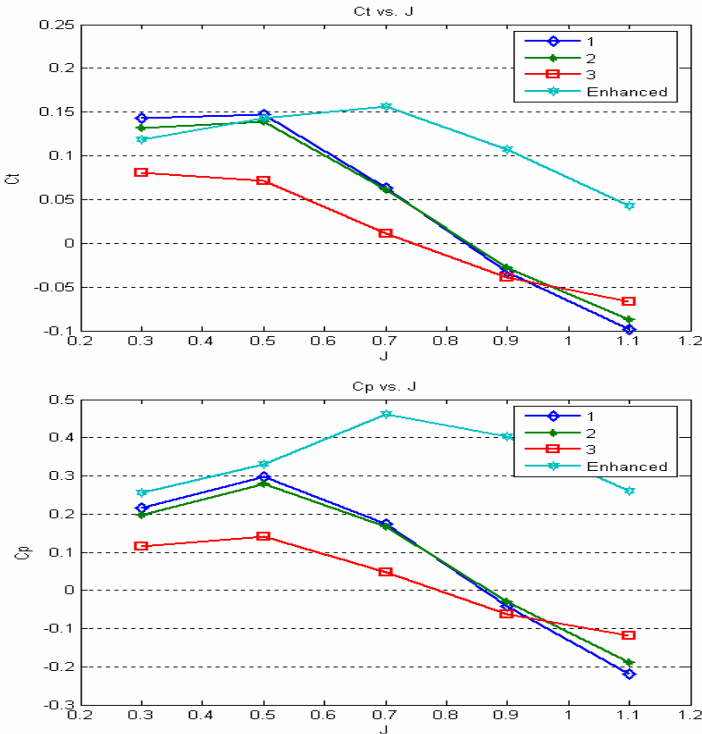

Figure 5 - Comparison of Various Propeller

Power System

Power Requirement-Table 5 shows the power/energy budget of the aerobot's flight during one Martian day, $70 \%$ electrical efficiency for the propulsion system has been included in the calculation, with $80 \%$ power conversion efficiency from the raw solar power. Rechargeable batteries will be responsible for the VTOL maneuver while solar cells will cover the cruise.

Table 5. Energy Requirement Per Day

\begin{tabular}{|c|c|c|c|c|}
\hline State & Operations & $\begin{array}{l}\text { Power } \\
\text { (W) }\end{array}$ & Duration & $\begin{array}{c}\text { Energy } \\
(\mathrm{kJ})\end{array}$ \\
\hline $\begin{array}{l}\text { Morning } \\
\text { Daytime }\end{array}$ & $\begin{array}{c}\text { Contact Experiments } \\
\text { Imaging } \\
\text { RF Communications } \\
\text { OBC } \\
\text { Battery Recharge } \\
\text { Average Solar Power }\end{array}$ & $\begin{array}{c}-15 \\
-5 \\
-30 \\
-50 \\
-70 \\
+303\end{array}$ & 3.5 hours & 1676 \\
\hline Take-off & $\begin{array}{l}\text { VTOL Propulsion } \\
\text { Forward Propulsion } \\
\text { Flight Control } \\
\text { Imaging } \\
\text { OBC } \\
\text { Average Solar Power }\end{array}$ & $\begin{array}{c}-5400 \\
-400 \\
-5 \\
-5 \\
-50 \\
+560\end{array}$ & 1 minute & -318 \\
\hline Cruise & $\begin{array}{l}\text { Forward Propulsion } \\
\text { Imaging } \\
\text { Flight Control } \\
\text { OBC } \\
\text { Average Solar Power }\end{array}$ & $\begin{array}{l}-580 \\
-5 \\
-5 \\
-50 \\
+548\end{array}$ & 1 hour & -331 \\
\hline Landing & $\begin{array}{c}\text { VTOL } \\
\text { Flight Control } \\
\text { Imaging } \\
\text { OBC } \\
\text { Average Solar Power }\end{array}$ & $\begin{array}{c}-5400 \\
-5 \\
-5 \\
-50 \\
+537\end{array}$ & 1 minute & -296 \\
\hline $\begin{array}{l}\text { Afternoon } \\
\text { Daytime }\end{array}$ & $\begin{array}{l}\text { Contact Experiments } \\
\text { Imaging } \\
\text { OBC } \\
\text { RF Communications } \\
\text { Battery Recharge } \\
\text { Average Solar Power }\end{array}$ & $\begin{array}{l}-15 \\
-5 \\
-50 \\
-30 \\
-80 \\
+280 \\
\end{array}$ & 3.5 hours & 1260 \\
\hline $\begin{array}{l}\text { Night } \\
\text { time }\end{array}$ & $\begin{array}{c}\text { OBC Monitoring } \\
\text { Thermal }\end{array}$ & $\begin{array}{c}-5 \\
-10 \\
\end{array}$ & 15 hours & -810 \\
\hline
\end{tabular}


Battery-As discussed earlier, a rechargeable battery will be needed for the VTOL maneuver, as well as for any periods of flight where the solar cells are shadowed. By comparing the specific energy of various battery technologies $(\mathrm{NiCd}$, $\mathrm{NiMH}, \mathrm{Li}$-ion, LiPo), the lithium type batteries stand out as the desirable options. Table 6 shows the typical properties of LiPo and Li-ion cells [22][23][24][25][26]. Although Liion can provide the desired high capacity, it cannot guarantee the high current needed in the VTOL manoeuvre.
One big advantage of LiPo over Lithium Ion is the ability to produce a high continuous current.

For each lift rotor, the power required is $1864 \mathrm{~W}$. Assuming that the battery efficiency is $70 \%$, then the total power needed from the battery would be $2700 \mathrm{~W}$. Taking KOK3200-2s as an example, this power could be delivered at $42 \mathrm{~V} \times 64 \mathrm{~A}$. For the given $7.4 \mathrm{~V}$ per pack, six packs in series are required per lift engine ( $=511 \mathrm{~kJ}$ capacity).

Table 6. Typical Properties of LiPo and Li-Ion Batteries

\begin{tabular}{|c|c|c|c|c|c|c|c|}
\hline \multirow{2}{*}{\multicolumn{2}{|c|}{ Battery }} & \multicolumn{3}{|c|}{ LiPo ( 2 cells in series) } & \multicolumn{3}{|c|}{ Li-Ion (1 cell) } \\
\hline & & KOK3200-2s & TP3200-2s & DSB180022 & MP 174865 & MP 144350 & GP1865L170 \\
\hline \multicolumn{2}{|l|}{ Voltage (V) } & 7.4 & 7.4 & 7.4 & 3.6 & 3.6 & 3.7 \\
\hline \multicolumn{2}{|l|}{ Dimension (mm) } & $42 \times 130 \times 16$ & $45 \times 130 \times 12$ & $34 \times 100 \times 30$ & $18.5 \times 48 \times 65$ & $13.5 \times 43 \times 50$ & $17 \times 67$ \\
\hline \multicolumn{2}{|l|}{ Capacity (mAh) } & 3200 & 3200 & 3600 & 4600 & 2300 & 1730 \\
\hline \multirow{2}{*}{$\begin{array}{l}\text { Max Discharge } \\
\text { Rate (A) }\end{array}$} & Continuous & 45 & $32-38$ & 26 & 9.2 & 4.6 & 2.4 \\
\hline & Pulse/Burst & 64 & 50 & 36 & 18.4 & 9.2 & -- \\
\hline \multicolumn{2}{|l|}{ Weight (g) } & 200 & 150 & 204 & 125 & 70 & 43 \\
\hline \multicolumn{2}{|c|}{ Specific Energy $(\mathrm{mAh} / \mathrm{g})$} & 16 & 21.3 & 17.65 & 36.8 & 32.86 & 40.2 \\
\hline
\end{tabular}

Solar Cell-The theoretical average insolation flux on Mars (above the atmosphere) is $583 \mathrm{~W} \cdot \mathrm{m}^{-2}$, while the local insolation will vary with latitude, sun angle and other environment conditions such as the amount of dust in the atmosphere. For these reasons, in our calculations we took the peak noon-time equatorial insolation to be a conservative $400 \mathrm{~W} \cdot \mathrm{m}^{-2}$. The effective daytime for solar power is around 10 hours at the equator. The total energy available per unit area per day at the equator is around 3 $\mathrm{kW} \cdot \mathrm{hr} \cdot \mathrm{m}^{-2}$ or $10.8 \mathrm{MJ} \cdot \mathrm{m}^{-2}$, which is in agreement with the estimation in [27].

Table 7 shows the performance of two candidate solar cell technologies: high-efficiency triple junction cells [28], and lightweight thin-film cells [29], which have the additional advantage of being flexible, and therefore can conform to the surface of the aircraft. The triple-junction cells have the advantage of high efficiency, but the specific power/mass is only $1 / 6^{\text {th }}$ that of the thin-film cells, hence thin-film solar cells are selected for this mission.

Table 7. Solar Cell Comparison

\begin{tabular}{|l|c|c|}
\hline Characteristics & Emcore & $\begin{array}{c}\text { NREL } \\
\text { Thin-Film }\end{array}$ \\
\hline Specific Power/Mass $\left(\mathrm{W} \cdot \mathrm{kg}^{-1}\right)$ & 131 & 478 \\
\hline Power/Area $\left(\mathrm{W} \cdot \mathrm{m}^{-2}\right)$ & 110 & 70 \\
\hline Mass/Area $\left(\mathrm{kg} \cdot \mathrm{m}^{-2}\right)$ & 0.84 & 0.1465 \\
\hline Efficiency & $27.5 \%$ & $17.5 \%$ \\
\hline Area Required $\left(\mathrm{m}^{2}\right)$ & 5.1 & 8 \\
\hline Mass $(\mathrm{kg})$ & 4.28 & 1.17 \\
\hline
\end{tabular}

\section{Payloads}

The payload options are numerous depending on the specific aim of each mission. A possible payload package is recommended in Table 8 [30][31][32][33][34][35][36].
Table 8. Payloads Package

\begin{tabular}{|l|r|}
\hline \multicolumn{1}{|c|}{ Instruments } & \multicolumn{1}{c|}{ Mass (g) } \\
\hline Contact Experiment & $\mathbf{1 9 7 0}$ \\
\hline Alpha Particle X-ray Spectrometer & 570 \\
\hline Mossbauer Spectrometer & 500 \\
\hline Optical Microscope & 300 \\
\hline Close-up Imager & 300 \\
\hline Abrasive Tool & 300 \\
\hline Imaging System & $\mathbf{1 0 3 0}$ \\
\hline Wide Angle Imagers (downwards) & 115 \\
\hline Wide Angle Imagers (forwards) & 115 \\
\hline 4 Narrow Angle Imager (downwards) & 800 \\
\hline \multicolumn{2}{|c|}{ Overall } \\
\hline
\end{tabular}

\section{Thermal Management}

The environment on Mars is well known for its low temperature. A typical Martian day temperature is from -90 at night to -20 at daytime. This places a strict constraint on various components of the Aerobot. Table 9 summarizes the operating temperatures of various components. As with previous Mars missions, a central warm core is required for the battery and other central electronics. Beyond this essential temperature-controlled inner, the majority of the vehicle can sustain operation at these typical Mars temperatures.

Ample insulation can be adopted to maintain the temperature of critical components, which then require only a very small amount of heating power. The insulation chosen is the highly insulative aerogel initially developed by NASA [37]. 
Table 9. Operation Temperature of Components

\begin{tabular}{|l|l|}
\hline Component & Temperature Range $\left({ }^{\circ} \mathbf{C}\right)$ \\
\hline Structure & $-190 \sim+150$ \\
\hline Motors & $-55 \sim+85(+160$ peak $)$ \\
\hline Solar Array & $-75 \sim+150$ \\
\hline Wiring & $-75 \sim+150$ \\
\hline CMOS Imagers & $0 \sim+60$ \\
\hline Payload & $-50 \sim+125$ \\
\hline Computer & $0 \sim+45$ \\
\hline Battery & $0 \sim+50$ \\
\hline
\end{tabular}

Besides the insulation and heating concerns, the cooling of motors and batteries during the one-minute VTOL maneuver is quite challenging. Assuming that $20 \%$ of the energy generated by battery is turned to heat; the battery temperature will be raised by about $25^{\circ} \mathrm{C}$ in one minute. This should not be a problem, as the battery should function adequately up to $+50^{\circ} \mathrm{C}$. The lift motor/rotor combination involves a particularly challenging thermal system on its own. In the morning the rotor will be initially cold along with the motor, but during take-off the motor will heat up rapidly, converting $\sim 10 \%$ of the input energy into heat. This energy will raise the motor temperature by over $60^{\circ} \mathrm{C}$. However, the cold start, and the short duration of the lift mean that it is unlikely that we would exceed the maximum acceptable motor temperature of $160^{\circ} \mathrm{C}$. The forward engine consume $20 \%$ of the lift engine energy

\section{Structural Design}

The preliminary design is that of a flying wing combined with a ducted propeller. The flying wing is chosen to ease the stowing in the aeroshell and gain higher lift/drag ratio. The wing is folded for storage in the aeroshell, shown in Figure 6. However, the structural layout of the Aerobot is still subject to changes as the analysis of its aerodynamic performance and stability progresses.

The airfoils used for conventional airplane usually have an inherent nose-down moment; hence a tail is necessary to balance the airplane. With regard to a flying wing configuration, a specially designed reflexed airfoil is required for stability reasons. Because of its preferable aerodynamic characteristics and its success in the model flying wing market, the Zagi 10 [38] is selected as the airfoil for the wing section. The aerodynamic characteristics are calculated using Javafoil code [39], results shown in Figure 7.

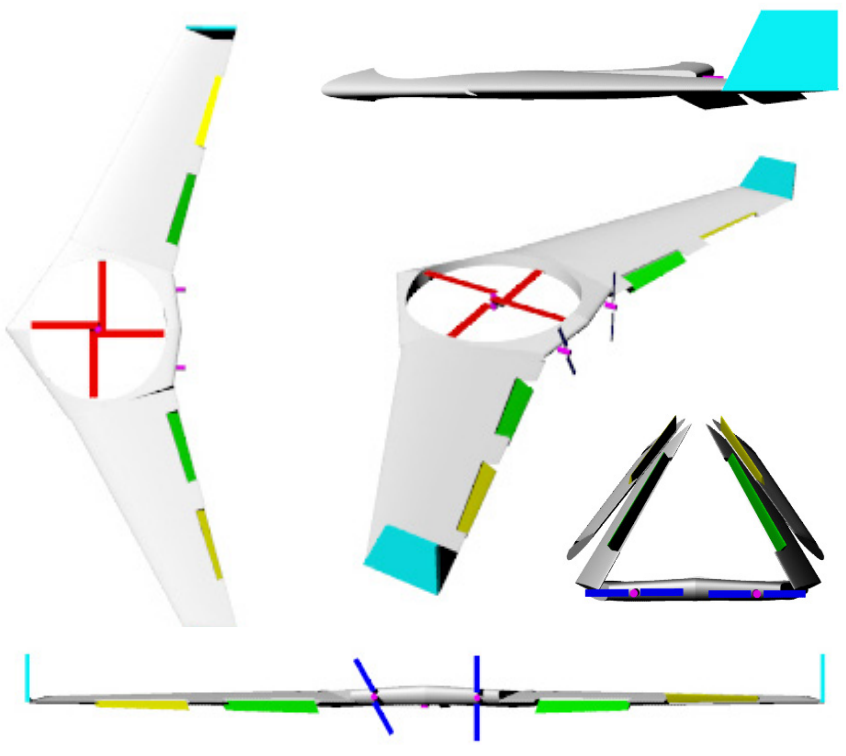

Figure 6 - Aerobot 3-D Layout
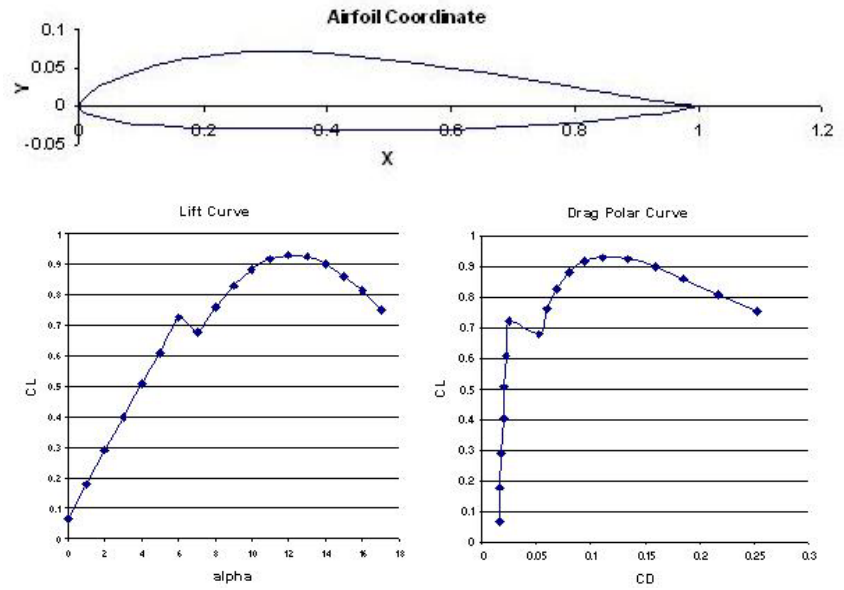

Figure 7 - Aerodynamic Characteristics of Zagi 10

\section{Mass Budget}

As investigated in previous sections, significant progress has been made recently in the critical fields for such a project: high specific power/mass thin-film solar cells [29]; high specific power/mass batteries [22]; lightweight and strong carbon fiber structural materials [40][41], Polystyrol, Hostaphan, Styrofoam etc. and their application in aircraft industrial [17][42][43][44]; lightweight thermal insulator [37] and the development of high-capacity and low-weight brushless DC motors for Terrestrial Unmanned Aerial Vehicles (UAVs) [18] etc. Furthermore, the development of miniaturized MEMS and CMOS sensors and the performance of single board computers will contribute to the miniaturized flight control system [35]. Hence, it is believed that the electrical aircraft proposed in this paper can be realized and the $25 \mathrm{~kg}$ mass budget can be achieved with the current technologies. 
Table 10. Mass Budget

\begin{tabular}{|l|c|}
\hline & Mass (kg) \\
\hline Propulsion & $\mathbf{6 . 0}$ \\
\hline Motors \& Gearboxs [18] & 1.5 \\
VTOL Rotors \& Forward Props [44] & 3.8 \\
Wiring, Controller \& Mounting & 0.7 \\
\hline Power & $\mathbf{3 . 9}$ \\
\hline Batteries [22] & 2.4 \\
Solar Array [29] & 1.2 \\
Wiring \& Regulator & 0.3 \\
\hline Structure & $\mathbf{1 0 . 9}$ \\
\hline Wing [17][42][43] & 7.8 \\
Body & 2.3 \\
Actuator, Controller \& Wiring & 0.8 \\
\hline Thermal Management & $\mathbf{0 . 2}$ \\
\hline Insulation & 0.1 \\
\hline Heating Devices & 0.1 \\
\hline Payload & $\mathbf{3 . 0}$ \\
\hline Contingency & $\mathbf{1 . 0}$ \\
\hline Total & $\mathbf{2 5}$ \\
\hline
\end{tabular}

\section{Control Strategy \& Sensor Suite}

The aerobot will have to take off, transition to cruise flight, transition to hovering flight and land, all without direct human control. An important aspect of the design is therefore the autonomous guidance, navigation and control (GNC) system.

The proposed aerobot will behave like a flying-wing in forward flight. A single control surface - i.e. an elevon looks to be simple, but is in actuality highly coupled and inefficient. So in this aerobot design, separate ailerons and elevators have been used.

The control of the VTOL maneuver is quite a challenge for this mission because of the unconventional configuration. By analyzing various schemes [15], a helicopter-style cyclic/collective control of the lift rotors is chosen for the VTOL maneuver due to its efficiency.

Autonomous localization and navigation of this Aerobot is still a big challenge due to the lack of GPS on Mars. A possible sensor suite might include: Inertial Measurement Unit with 3-axis accelerometers and 3-axis gyroscopes; air speed sensor and altimeter based on airdata; fisheye imagers for calibrating the attitude angles; sun sensor for rough correction and additional landmark and vision-based system for optical flow and collision avoidance.

The GNC system is still under investigation as a separate study. In the following sections, the dynamics and control of the forward flight will be discussed.

\section{DYNAMICS}

A six-degree-of-freedom flight simulator has been created in SIMULINK [52] to support the Aerobot design process by providing performance evaluations. The flowchart is shown in Figure 8.

1. The initial conditions and control inputs are first incorporated into the system;

2. The Aerodynamics and Propulsion Models will calculate the corresponding forces and moments;

3. These forces and moments are then input into the Equations of Motion to solve for the corresponding behaviour of the aerobot (i.e. the states of the aerobot);

4. The state outputs are then fed back to the Martian Atmosphere Model to update the atmospheric parameters in current conditions, and to Aerodynamics and Propulsion Models for the next step calculation from step 2.

The simulation is an iterative process.



Figure 8 - Simulation Flowchart

\section{Modelling of Dynamics}

Aerodynamic Model-The aerodynamic model utilizes linear aerodynamics in which the aerodynamic force and moment coefficients are computed as linear combinations of aerodynamic derivatives with various flight parameters [45]. There are various methods to obtain the aerodynamic derivatives including: analytical method, semi-empirical equations, Computational Fluid Dynamics (CFD) method, and experimental methods. In this paper, the aerodynamic coefficients are obtained by the Vortex Lattice method [46] and DATACOM [47].

Propulsion Model-The thrust and moment coefficients of propeller are calculated as linear 1-D interpolations using the look-up tables of $C_{t}$ vs. $J$ and $C_{p}$ vs. $J$ as shown in Figure 5 for the fixed-pitch propeller.

Equation of Motion-The Equations of Motion include the standard 6-DOF equations used for conventional aircraft control design and flight simulation, i.e. twelve differential equations including: force equations, kinematic equations, moment equations and navigation equations [48]. In this model, the kinematics equations are changed to the Euler- 
Rodrigues quaternions [49], as quaternion equations are linear and the solution is free from the singularity exhibited with simple Euler angle equations.

Martian Standard Atmosphere-The Martian Atmosphere is modelled as fit equations published by NASA, which is valid for the flight below 7000m [50]. A more sophisticated model of Martian atmosphere is also available from ESA [8]. But for this research, as the cruise altitude would be around $1000 \mathrm{~m}$, the NASA's equation is considered to be sufficiently accurate.

\section{Results and Discussions}

Longitudinal Behavior - Given an arbitrary initial condition, the simulation will converge to a steady state, i.e. the equilibrium point. The deflection of the elevator will disturb the aerobot from its equilibrium point, but it will soon converge to another point. Figure 9 shows how the aerobot behaves after the elevator is deflected upwards by 1 degree, where the red dashed line represents the initial equilibrium point and the blue solid line represents the aerobot's state over time. With 1-degree deflection upwards of elevator, the velocity converges to a value lower by $0.5 \mathrm{~ms}^{-1}$, and the angle of attack $\alpha$ and pitch angle $\theta$ converge to a higher value. As the converged value of $\theta$ is higher than $\alpha$, the aerobot started to climb as shown in the height plot.

Lateral/Directional Behavior - As this aerobot is symmetric about the X-Z plane, it appears to be dynamically neutral in the lateral/directional mode at first sight. However, once the aerobot is disturbed by an aileron or rudder step input or an initial bank angle, this balance will be broken immediately. Without control input, it quickly goes into a spiral dive mode as shown in Figure 10 and Figure 11.
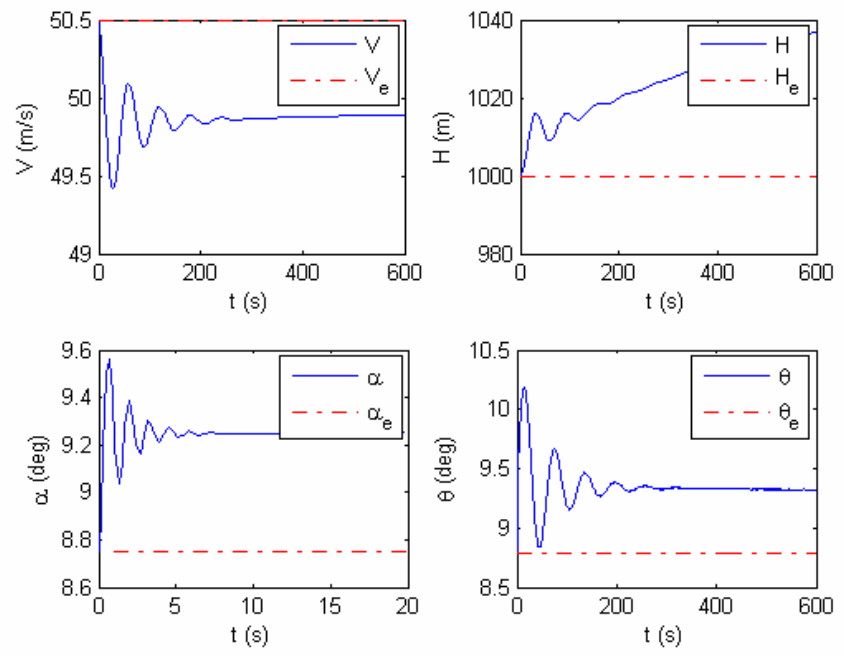

Figure 9 - Longitudinal Behavior with Elevator Deflection (Step Response)
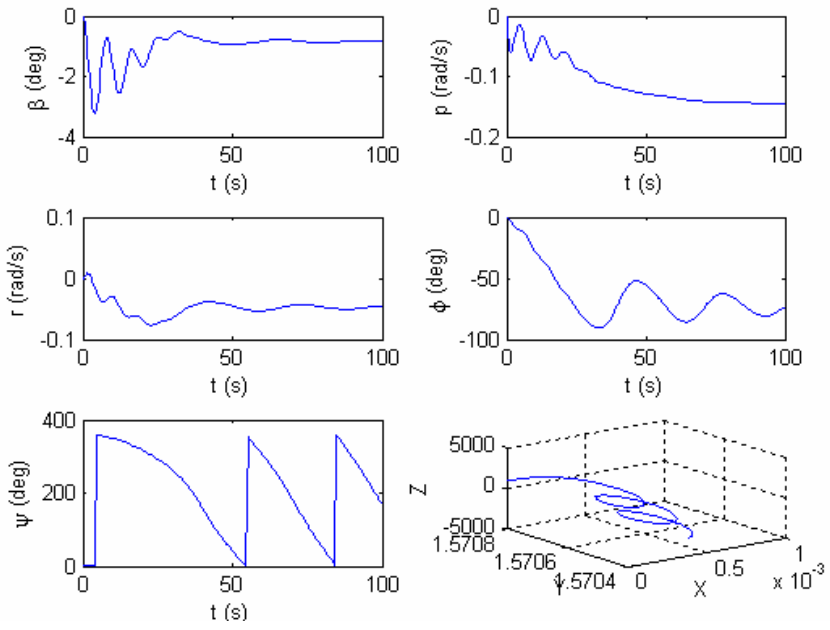

Figure 10 - Lateral/Directional Behavior with Aileron Deflection


Figure 11 - Lateral/Directional Behavior with Rudder Deflection (Step Response)

\section{Control}

In the following sections, the longitudinal and lateral/directional controllers' design will be discussed. The design methods used are the classical root locus analysis, frequency domain method, and the time domain method, with additional trial-and-error.

\section{Linearized State-Space Dynamics vs. Nonlinear Dynamics}

Firstly, the nonlinear dynamic model is linearized to a state space formulation. The step responses of nonlinear and linearized model are shown in Figure 12. This shows that the linearized model is in agreement with the nonlinear model, which suggests that this linearized model is sufficiently accurate for the controller design. 

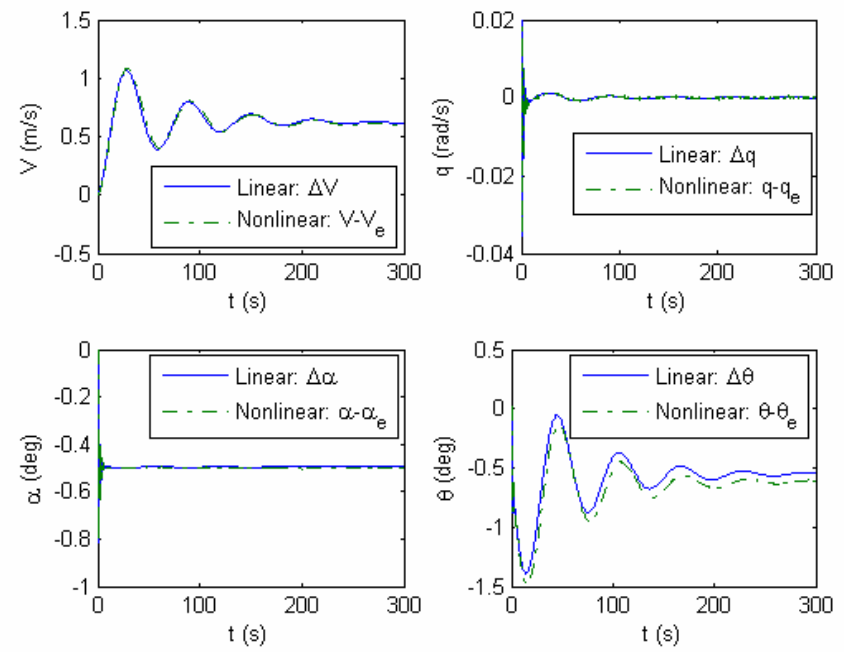

Figure 12 - Elevator Step Response



Figure 13 - Pitch Attitude Hold ( $\theta$-loop)

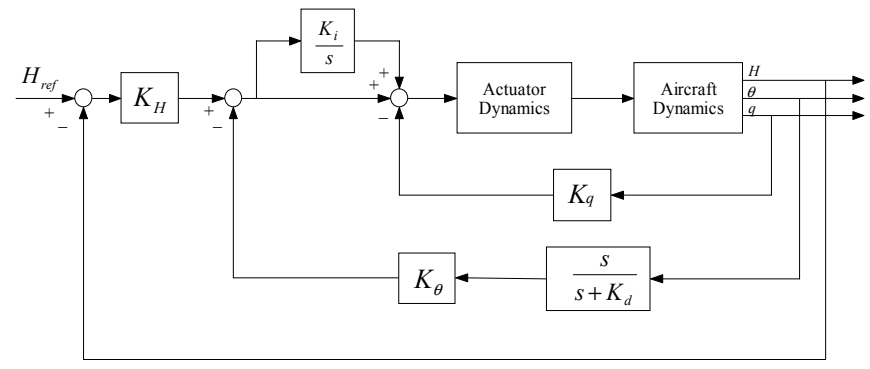

Figure 14 - Altitude Hold (H-loop)

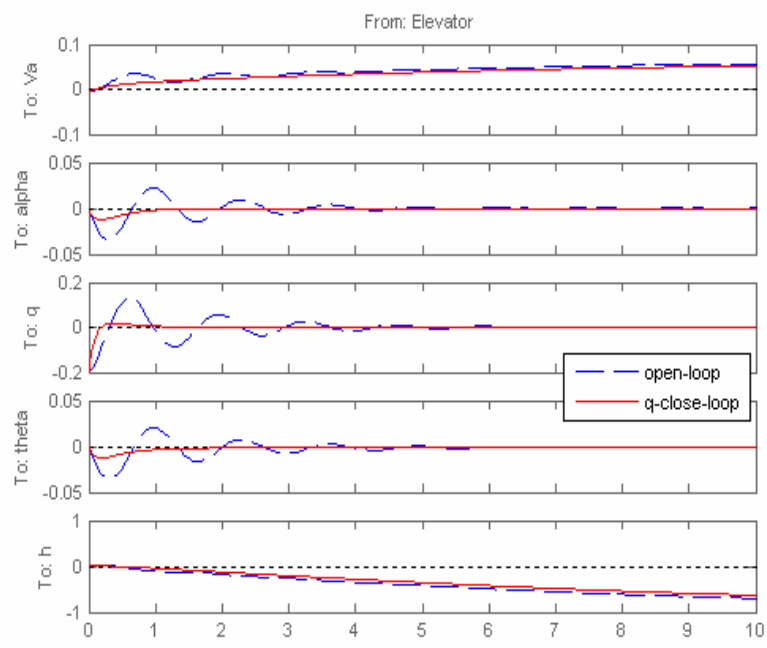

Figure 15 - Impulse Response (open-loop vs. q-loop)
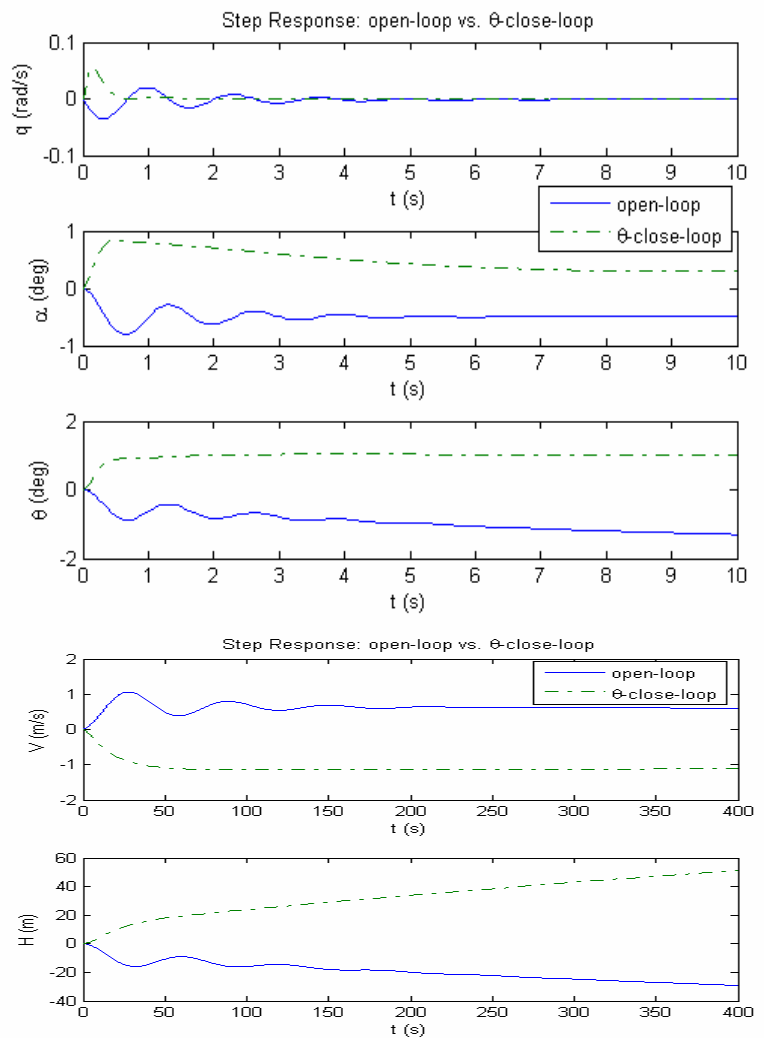

Figure 16 - Step Response (open-loop vs. $\theta$-loop)


Figure 17 - Step Response (open-loop vs. H-loop) 


\section{Longitudinal Controller Design}

Based on this state space model, two mode controllers are investigated: Pitch Attitude Hold (PAH) and Altitude Hold (ALH), as shown in Figure 13 and 14.

The PAH is the basic longitudinal autopilot mode. It controls the pitch angle by applying appropriate deflection to the elevator if the actual pitch angle differs from the desired reference values. The pitch rate $q$ and pitch angle $\theta$ are chosen as feedback variables. A feedback-loop of $q$ to the elevator has been included to damp the short-period mode. The impulse response of $q$-loop is shown in Figure 15 . Obviously, the $q$-loop expedites the damping greatly. The pitch angle $\theta$ is fed back to damp the phugoid mode of the aerobot and to ensure that the desired pitch angle is maintained. A proportional and integrator (PI) controller is applied in order to eliminate the steady-state errors in $\theta$.

The ALH is used to maintain a reference/desired altitude. It fulfills a basic guidance function of the aerobot. This mode uses the PAH with an additional washout filter in the $\theta$-loop as the inner loop. The difference between the reference altitude and the actual altitude, $\Delta H=H_{\text {ref }}-H$, is fed back via an amplifier to the inner loop, hence, the outer loop generates a pitch command $\theta_{\text {ref }}$ for the inner loops. An additional washout filter is added to prevent $\theta$ from sticking to the zero.

Figure 16 and 17 shows the step response of $\theta$-loop (PAH) and H-loop (ALH) respectively. In PAH mode, $\theta$ successfully converges to the given reference step input after 2 seconds, whereas the open-loop dynamics will oscillate for a while and converge to a wrong state. In ALH, the altitude converges to the reference step input after 50 seconds. The overshoot is within $25 \%$.

\section{Lateral/Directional Controller Design}

Two directional / lateral controllers are investigated, Yaw Damper (YD) and Bank Angle Hold (BAH) [48][51].

Yaw Damper is the basic lateral/directional stabilizer to damp roll and yaw oscillations due to Dutch roll by applying appropriate deflection to the rudder. Besides a reasonable gain, it is also augmented with a washout filter. The impulse response of the YD is shown in Figure 18. The YD expedites the damping greatly.

Bank Angle Hold is a basic lateral/directional autopilot mode. It controls the bank angle by applying appropriate deflection to the aileron if the actual bank angle $(\phi)$ differs from the desired reference values. The Roll Damper is included as an inner-loop to damp the short-period mode, results shown in Figure 19. A PI controller is applied in order to eliminate the steady-state errors in $\phi$. The impulse response of the BAH is shown in Figure 20. The step response of the BAH is shown in Figure 21. The open-loop will converge to a wrong state, whereas the BAH helps the aerobot to gain and maintain the given bank angle.

\section{Further Discussions}

As the directional and lateral dynamics are highly coupled, it is not adequate to just design and analyze them separately. The truth is: when the two controllers are integrated into one system, it doesn't work as well as expected. This is because the controllers are designed individually without considering the coupling effect. Further investigation of modern design control methods is necessary in order to design the various controllers simultaneously.

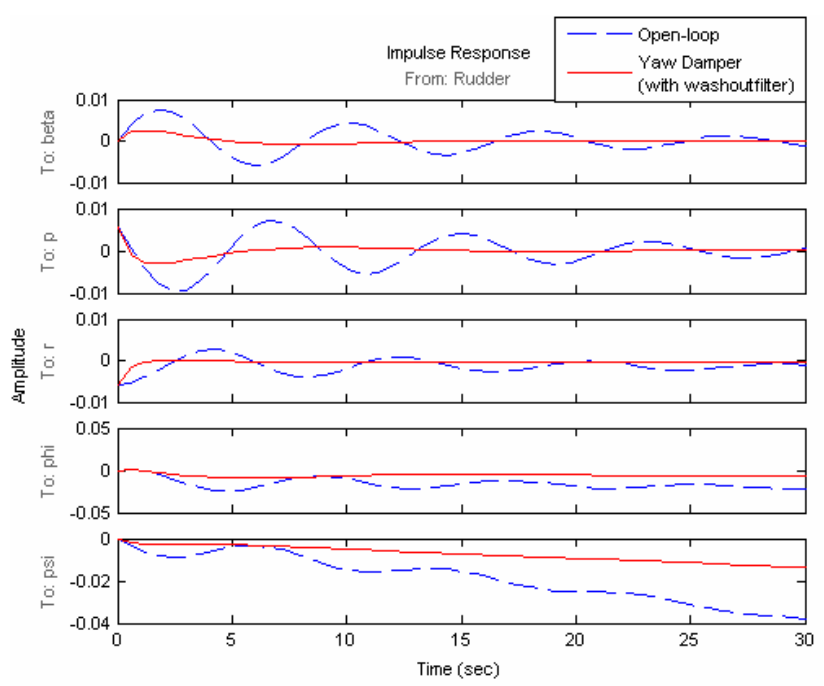

Figure 18 - Impulse Response (Open-loop vs. Yaw Damper)



Figure 19 - Impulse Response (Open-loop vs. Roll Damper) 


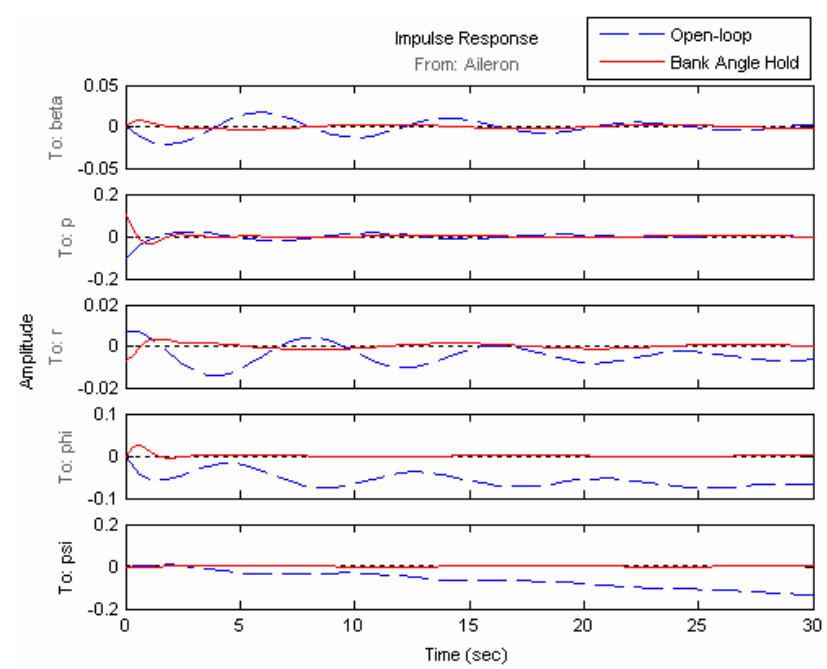

Figure 20 - Impulse Response (Open-loop vs. BAH)

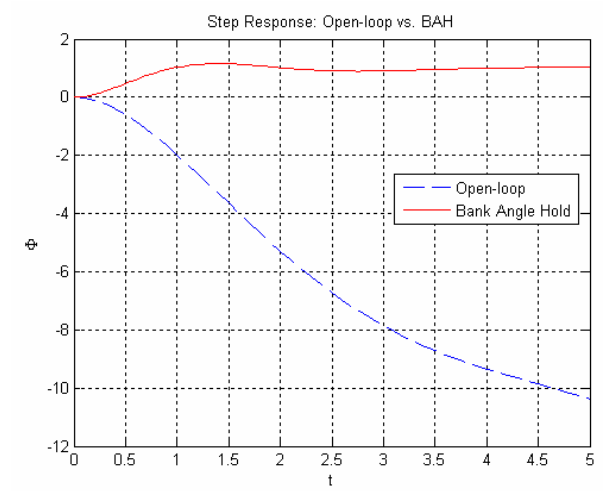

Figure 21 - $\phi$ Step Response (Open-loop vs. BAH)

\section{FUTURE WORK}

The dynamics and controller of the VTOL maneuver needs to be developed. It may lead to a displacement of the centre of gravity. The other difficulty lies in the transition between the VTOL and forward flight modes. One solution might be: gain some height first, then dive the aerobot to gain velocity, at some point increase the angular velocity of the motor to gain altitude. The ground effect should also be investigated for possible utilization.

The controller design in this paper used classical linear control methods such as root locus analysis, pole placement, frequency domain method, time domain method and trialand-error. The essence is the successive loop closure, which would require lots of intuition and experience in selecting the control system structure and feed back signals. The control gains are selected individually through one loop at a time. As more loops were added, the design procedure become increasingly difficult and are very likely to fail when the dynamics are multivariable, which is obviously noticeable in the Lateral/Directional Controller. Modern control design such as Linear Quadratic Regulator (LQR), Linear Quadratic Gaussian (LQG), Linear Matrix Inequality
(LMI), Receding Horizon Control (RHC), Dynamic Inversion (DI) etc need to be investigated.

The mode controllers presented in this paper is just the fundamental level of an autopilot. The navigation, and localization are under investigation by another $\mathrm{PhD}$ student in Surrey Space Centre [53]. The initial thought is to use machine vision system for navigation and localization purposes.

\section{CONCLUSION}

In this paper, we propose the use of a novel fixed wing vertical take-off and landing (VTOL) aerobot. A mission profile to investigate the Isidis Planitia region of Mars is proposed based on the knowledge of the planet's geophysical characteristics, its atmosphere and terrain. The fixed wing VTOL capability is explored, showing that this combination uniquely allows for multiple flights, long endurance, high-resolution imagery and multiple surface sampling. The Aerobot takes advantage of the electrical motor/propeller for both the VTOL and forward flight propulsion, using solar cells to provide the power for forward flight, and for recharging the flight batteries for the high-power-demand VTOL manoeuvres. The power system uses a combination of the state-of-the-art rechargeable battery and thin film solar cell technology. The suggested $3 \mathrm{~kg}$ payload would accomplish a basic scientific investigation and provide valuable information in searching for life. The preliminary structural layout is a flying wing combined with a coaxial contra-rotating ducted propellers, but this may be subject to minor changes as the analysis of its aerodynamic performance and stability progresses. A mass budget of $25 \mathrm{~kg}$ is shown to be achievable with the current technologies. The Aerobot design proposed in this paper is believed to be a practical and realistic solution to the problem of investigating the Martian surface.

A six-degree-of-freedom flight simulator has been created to support the Aerobot design process by providing performance evaluations. The Vortex Lattice method is used to obtain the stability derivatives. An important aspect of the design is the autonomous guidance and control system. Two longitudinal control modes are investigated and the controller proves to be effective. The results of the simulation would seem to indicate that the Aerobot design is appropriate and is a suitable aerial platform to carry out the mission profile. 


\section{REFERENCES}

[1] Vargas A., Evrard J., Mauroy P, "Mars 96 Aerostat - An Overview of Technology Development and Testing," AIAA-97-1449, 1997.

[2] Kerzhanovich V.V., Cutts J.A., et.al, "Breakthrough in Mars Balloon Technology," Advances in Space Research 33, pp. 1836-1841, 2004.

[3] Gundlach IV IV J.F. "Unmanned Solar-Powered Hybrid Airships for Mars Exploration,” AIAA-99-0896, 1999.

[4] ARES Website, http://marsairplane.larc.nasa.gov/

[5] Wright H.S., Croom M.A., et.al, “Ares Mission Overview - Capabilities and Requirement of The Robotic Aerial Platform," AIAA-2003-6577, 2003

[6] Young L.A., Aiken E.W, "Vertical Lift Planetary Aerial Vehicles: Three Planetary Bodies and Four Conceptual Design Cases," Presented at 27th European Rotorcraft Forum, Moscow, Russia, 2001

[7] Fielding J, MASSIVA: MArs Surface Sampling and Imaging Vtol Aircraft, PhD thesis, University of Surrey, UK, 2004

[8] The Martian Climate Database Website, http://wwwmars.lmd.jussieu.fr/

[9] Tillman J.E, Mars website, http://wwwk12.atmos.washington.edu/k12/resources/mars_datainformation/pressure_overview.html

[10] MSSS website http://www.msss.com/mage_release/index.html

[11] Hall D.W., Parks R.W., Morris S, “Airplane for Mars Exploration, Conceptual Design of the Full-Scale Vehicle Design, Construction and Test of Performance and Deployment Models," Submitted to NASA/Ames Research Center, 1997

[12] Smith S.C., "The Design of the Canyon Flyer, An Airplane for Mars Exploration," AIAA 2000-0514, 38th Aerospace Sciences Meeting \& Exhibition, Reno N, 2000

[13] NASA Ames Website, http://www.nasa.gov/centers/ames/home/index.html

[14] Smith D.E., "The Global Topography of Mars and Implications for Surface Evolution," 1999

[15] Song, H, "Autonomous Guidance and Control of a Mars Vtol Aerobot," Transfer report, Surrey Space Centre, University of Surrey, 2005
[16] Wickman J, “WSPC Invents Martian Jet Engine Burns Carbon Dioxide," Company news article, http://www.space-rockets.com/marsjet.html

[17] Dryden, "Helios Prototype: The forerunner of 21st century solar-powered "atmospheric satellites"," Dryden Flight Research Center, FS-2002-08-068 DFRC, NASA.

[18] Aveox Website, http://www.aveox.com/

[19] http://www.vstol.org/

[20] Leishman J. Gordon, Principle of Helicopter Aerodynamics, 2000

[21] UIUC Airfoil Data Site, http://www.ae.uiuc.edu/mselig/ads.html

[22] Kokam Website, http://www.aurorra.co.uk/shop/2/index.htm

[23] Thunderpower Website, http://www.thunderpowerbatteries.com $/ \mathrm{html} /$ batteries.html

[24] Modelflight Website, http://www.modelflight.com.au/lithium_ion_polymer.htm

[25] SaftBattery Website, http://www.saftbatteries.com/130Catalogue/PDF/mp.pdf

[26] GPbattery Website, http://www.gpbatteries.co.uk/home.htm

[27] Landis G.A., Appelbaum J, "Photovoltaic power Options for Mars," Space power, Volume 10, Number 2, pp 225237, 1991

[28] Emcore, "Advanced Triple-Junction (ATJ) High Efficiency Solar Cells for Space Application," Product Brief, 2004

[29] NREL Website, "NREL World Record Thin-Film Cell Efficiency," http://www.nrel.gov/ncpv/pdfs/tf_nrel2.pdf

[30]Rieder R, Wanke H., etc., "Determination of the chemical composition of Martian soil and rocks: The alpha proton X ray spectrometer," Journal of Geophysical Research, Volume 102, Issue E2, p. 40274044, 1997

[31] Black A. Blancy P. ect., “An Integrated Exobiology Package For The Search For Life On Mars," Advance Space Res. Vol. 23, No.2, p. 301-308, 1999

[32] Stroupe A. W., "Icebreaker Scientific Package: A Proposed Scientific Instrument Suite For A Lunar Polar Mission," DMU-RI-TR-99-28, The Robotics Institute, Carnegie Mellon University, 1999 
[33] Kim S. S. and Hayati S. etc., "Mars Miniature Science Instruments," IEEE Aerospace Conference, 2006

[34] Westalla F., Brack A., "An ESA study for the search for life on Mars," Planetary and Space Science 48, 2000

[35] Vaglienti B., Hoag R., "A Highly Integrated UAV Avionics System,” Cloud Cap Technology Inc, 2003

[36] Devantech SRF04 Sonar Ranger, http:/www.acroname.com/robotics/parts/R93SRF04.html

[37] Thermal Properties of Silica Aerogels, http://eetd.lbl.gov/ECS/aerogels/satcond.htm

[38] Zagi Website, http://www.zagi.com/index.php

[39] JAVAFOIL Website, http://www.mh-aerotools.de/

[40] Netcomposites Website

http://www.netcomposites.com/education.asp? sequence $=30$

[41] Quorumtech Website http://www.quorumtech.com/Products/carbonrods.htm

[42] Human Power Flight, http://www.skytec-engineering.de/hpa.htm

[43] Frank P., "The Human Powered Aircraft Velair Design Details and Result of Structural, Prop and Flight Tests," AIAA International human powered flight symposium Seattle Washington, USA, August 1994.

[44] Bolly, http://www.bolly.com.au/optima/seriesone.html

[45] Frederick O. Smetana, Flight Vehicle Performance and Aerodynamic Control, AIAA Education Series, 2001

[46] MIT website, http://web.mit.edu/drela/Public/web/avl/

[47] AFFDL-TR-79-3032: The USAF Stability and Control DATCOM, Volume 1, Users Manual

[48] Stevens B. L., Lewis F. L., Aircraft Control and Simulation, John Wiley \& Sons, Inc., 1992

[49] Phillips W. F. Hailey C. E. and Gebert G. A., Review of Attitude Representations Used for Aircraft Kinematics, Journal of Aircraft, 38:718-737, 2001

[50] Mars Atmosphere Model, NASA Website http://exploration.grc.nasa.gov/education/rocket/atmosmr m.html

[51] Etkin B., Reid L.D., Dynamics of Flight: Stability and Control, John Wiley \& Sons, Inc, 2001
[52] Matlab Online Help Documents

[53] Chen J.H., "Machine Vision For Mars Aerobot Optical Localization \& Navigation," Transfer Report, Surrey Space Centre, UK, 2006

\section{BIOGRAPHY}

Hanbing Song received the B.E. and M.E. degrees from

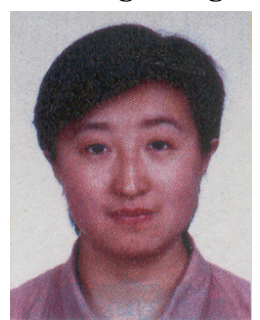
Northwestern Polytechnical University, Xi'an, China, in July 2000 and in July 2002, respectively. She has also received a M.S. degree from SingaporeMIT Alliance, National University of Singapore, in June 2003. From November 2003 to September 2003, She worked in the Nanyang Technological University, Singapore. She is currently a PhD student in Surrey Space Centre, University of Surrey, United Kingdom. Her research interest is Martian Aerobot.

Dr Craig Underwood graduated from the University of

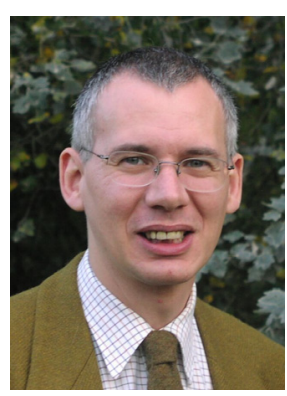
York in 1982 with a B.Sc.(Hons) in Physics with Computer Science In January 1986, Craig joined the University of Surrey Space Centre as a Research Fellow working on the development of micro-satellite and micro-sensor technology. He gained his Ph.D in Space Radiation Environment and Effects in 1996. In 1993, Craig became a Lecturer in Spacecraft Engineering advancing to Senior Lecturer in 1999, and Reader in April 2003. Craig heads the Planetary Environments Group within the Surrey Space Centre, which has the remit of developing the instruments, systems and data processing techniques needed to investigate the Earth and other planetary environments from space. 